\title{
Dampak Kualitas Pelayanan Terhadap Kepuasan Pasien Puskesmas
}

\section{Imran 1*, Yulihasri2*, Almasdi3* Yimmi Syavardie ${ }^{4 *}$}

\author{
1,2 Universitas Andalas, Padang,Indonesia \\ 1,3,4 ITB Haji Agus Salim,Bukittinggi, Indonesia
}

\section{ART I CLE INF O}

Article history:

Received August 22, 2021

Revised August 29, 2021

Accepted October 12, 2021

Available online October 25, 2021

Kata Kunci:

Kualitas Pelayanan, Kepuasan

Pasien

Keywords:

Service Quality, Patient Satisfaction

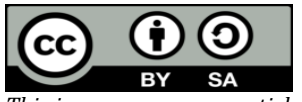

This is an open access article under the $C \mathrm{CC}$ $B Y$-SA license.

Copyright (c) 2021 by Author. Published by Universitas Pendidikan Ganesha.

\begin{abstract}
A B S T R A K
Kualitas pelayanan yang disebabkan oleh sumber daya manusia, fasilitas, dan rujukan yang belum optimal. Penelitian ini bertujuan untuk mengetahui pengaruh kualitas pelayanan terhadap kepuasan pasien Puskesmas. Jenis penelitian ini adalah penelitian kuantitatif dengan metode asosiatif. Populasi dalam penelitian ini adalah seluruh pengunjung yang datang ke Puskesmas. Pengambilan sampel dailakukan dengan teknik purposive sampling. Adapun mjumlah sampel yang digunakan dalam penelitian ini adalah 100 responden. Teknik pengumpulan data yang digunakan yaitu kuesioner dengan skala likert. Teknik analisi yang dilakukan dengan metode analisis regresi berganda dengan menggunakan SPSS. Hasil penelitian menujukkan bahwa dimensi tangible mempunyai pengaruh yang signifikan terhadap kepuasan pasien, dimensi reliable mempunyai pengaruh yang signifikan terhadap kepuasan pasien, dimensi responsiveness mempunyai pengaruh yang signifikan terhadap kepuasan pasien, dimensi anssurane mempunyai pangruh yang signifikan terhadap kepuasan pasien, dimensi emphaty mempunyai pengaruh yang signifikan terhadap kepuasan pasien. Dimensi yang paling dominan pengaruh yaitu tangible, sedangkan yang paling rendah yaitu responsiveness. Dimensi tangible, reliable, responsiveness, assurance dan emphaty secara simultan mempunyai pengaruh yang signifikan terhadap kepuasan pasien. Hasil penelitian diharapkan agar pihak pengelolan Puskesmas Banja Loweh Kabupaten Lima Puluh Kota lebih meningkatkan kualitas pelayanan terutama pada dimensi responsiveness yang paling rendah.
\end{abstract}

\begin{abstract}
A B S T RACT
The quality of service is caused by human resources, facilities, and referrals that are not optimal. This study aims to determine the effect of service quality on patient satisfaction at the Puskesmas. This type of research is quantitative research with associative method. The population in this study were all visitors who came to the Puskesmas. Sampling was done by purposive sampling technique. The number of samples used in this study were 100 respondents. The data collection technique used is a questionnaire with a Likert scale. The analysis technique is carried out by using multiple regression analysis method using SPSS. The results show that the tangible dimension has a significant influence on patient satisfaction, the reliable dimension has a significant influence on patient satisfaction, the responsiveness dimension has a significant influence on patient satisfaction, the insurance dimension has a significant influence on patient satisfaction, the empathy dimension has a significant influence. on patient satisfaction. The most dominant dimension of influence is tangible, while the lowest is responsiveness. The dimensions of tangible, reliable, responsiveness, assurance and empathy simultaneously have a significant influence on patient satisfaction. The results of the study are expected that the management of the Banja Loweh Public Health Center, Lima Puluh Kota Regency will further improve the quality of service, especially in the lowest dimension of responsiveness.
\end{abstract}

\section{PENDAHULUAN}

Masalah kesehatan menjadi hal yang sangat utama saat ini. Peningkatan taraf hidup masyarakat, disertai dengan meningkatnya pula tuntutan masyarakat akan kualitas kesehatan yang diharapkan. Seiring perkembangan dinamika kehidupan dunia usaha semakin keras dan ketat termasuk di bidang pelayanan kesehatan terutama Rumah Sakit, baik Rumah Sakit Swasta maupun Rumah Sakit Pemerintah dan tidak terlepas juga dalam hal ini Puskesmas (Anjayati, 2021; Tores, 2018). Puskesmas dituntut untuk meningkatkan mutu pelayanan yang lebih baik, tidak hanya pelayanan yang bersifat penyembuhan penyakit tetapi juga meliputi pelayanan yang bersifat pencegahan (preventif) untuk meningkatkan mutu hidup serta memberikan kepuasan bagi konsumen selaku pengguna jasa kesehatan. Selain itu, puskesmas dituntut untuk selalu meningkatkan profesionalitas dari pegawainya serta meningkatkan fasilitas atau sarana kesehatannya. Fasilitas pelayanan kesehatan adalah suatu alat atau tempat yang digunakan untuk menyelenggarakan upaya pelayanan kesehatan, baik promotif, preventif, kuratif maupun rehabilitatif yang 
dilakukan oleh pemerintah, pemerintah daerah, dan masyarakat (Engkus, 2019a, 2019b; Tores, 2018). Peningkatan mutu pelayanan juga perlu dilakukan oleh unit pelayanan kesehatan di setiap Puskesmas yang ada di Indonesia agar, kepuasan pelanggan terpenuhi secara maksimal (Setryorini, 2018). Oleh karena itu perlu dibangun suatu sistem yang baik dalam pelayanan guna mengarahkan Puskesmas untuk melakukan pengukuran, monitoring, pengendalian, pemeliharaan, penyempurnaan yang berkelanjutan, dan pendokumentasian. Sistem tersebut disebut dengan Sistem manajemen mutu, dengan adanya sistem manajemen mutu yang berjalan dengan baik, maka akan memandu sistem pelayanan di Puskesmas untuk mematuhi standar, pedoman, dan peraturanperaturan yang berlaku dalam penyelenggaraan pelayanan kepada masyarakat (O. Dewi et al., 2021; Nuryati, 2017).

Kualitas pelayanan merupakan tingkat keunggulan yang diharapkan dan pengendalian atas tingkat keunggulan tersebut untuk memenuhi harapan pelanggan (Haryoko et al., 2020; Ofela, 2016). Kualitas pelayanan yang dirasakan merupakan hasil dari perbandingan kinerja dan yang diterima konsumen dari penyedia jasa (Enas, 2020). Kepuasan konsumen merupakan modal dasar untuk membentuk loyalitas yang bisa dijadikan sebagai salah satu senjata untuk menaikan keunggulan bersaing suatu perusahaan yang bergerak di sektor jasa (Darmawan \& Ekawati, 2017; Ofela, 2016). Bila ditinjau dari sudut pandang perusahaan, salah satu cara yang efektif dalam melakukan diferensiasi adalah melalui jasa atau pelayanan yang diberikan. Hal ini membawa perubahan yang cukup mendasar dalam bisnis utama suatu perusahaan maupun suatu instansi kesehatan. Kepuasan pelanggan adalah suatu keadaan dimana keinginan, harapan dan kebutuhan pelanggan dipenuhi (O. Dewi et al., 2021; Rafiah, 2019). Suatu pelayanan dinilai memuaskan bila pelayanan tersebut dapat memenuhi kebutuhan dan harapanpelanggan. Pengukuran kepuasan pelanggan merupakan elemen penting dalam menyediakan pelayanan yang lebih baik, lebih efisien dan lebih efektif. Apabila pelanggan merasa tidak puas terhadap suatu pelayanan yang disediakan, maka pelayanan tersebut dapat dipastikan tidak efektif dan tidak efisien. Hal ini terutama sangat penting bagi pelayanan publik (Puskesmas). Semakin ketatnya persaingan serta pengguna yang semakin selektif dan berpengetahuan mengharuskan Pusat Kesehatan Masyarakat (Puskesmas) selaku salah satu penyedia jasa layanan kesehatan untuk selalu meningkatkan kualitas layanannya. Untuk dapat meningkatkan kualitas pelayanan, terlebih dahulu harus diketahui layanan yang telah diberikan kepada pasien / pelanggan selama ini telah sesuai dengan harapan pasien / pelanggan atau belum.

Namun kenyataannya, kualitas pelayanan yang disediakan oleh Puskesmas Banja Loweh di Kabupaten Lima Puluh Kota belum terlaksa dengan optimal. Seara umum masih terdapat kekurangan. Berdasarkan hasil pengamatan yang dilakukan, peneliti menemukanan beberapa masalah yang merujuk ke dalam dimensi kepuasan pasien terkait akses layanan kesehatan, fasilitas ruangan yang tidak memadai terutama ruang tunggu pasien, dokter cenderung memebrikan obat yang sama, proses pelayanan yang lambat dan kurang ramah dan pembuatan surat rujukan BPJS yangukup lama karena jaringan internet yang buruk. Banyak anggota masyarakat yang mengeluh dan merasa tidak puas dengan pelayanan yang diberikan oleh Puskesmas milik pemerintah ini baik itu dari segi pemeriksaan yang kurang diperhatikan oleh petugas kesehatan, lama waktu pelayanan, keterampilan petugas, sarana/fasilitas, serta waktu tunggu untuk mendapatkan pelayanan (Sukarni et al., 2020). Sangat penting bagi rumah sakit untuk terus mengukur kualitas pelayanan terhadap kepuasan pelanggan sehingga dapat mengidentifikasi area-area yang memerlukan perbaikan dan mengetahui apakah pelanggan/pasien puas atau tidak. Selanjutnya rumah sakit perlu mengetahui faktor-faktor yang secara keseluruhan mempengaruhi kepuasan pasien/pelanggan dan menentukan persepsi pelanggan terhadap determinan-determinannya agar dapat memberikan kualitas pelayanan yang tinggi kepada pelanggan (Neupane \& Devkota, 2017). Untuk meningkatkan sistem kesehatan dan memastikan bahwa pasien menerima kualitas layanan yang mereka butuhkan, analisis kepuasan pasien yang dibuat sangat penting untuk manajer layanan kesehatan dan analisis kebijakan (AlAzzam, 2020).

Solusi yang dapat dilakukan yaitu kualitas pelayanan kesehatan perlu ditingkatkan karena kebutuhan masyarakat atau perorangan terhadap kesehatan yangsesuai dengan standar dengan pemanfaatan sumber daya secara wajar, efisien, efektif dalam keterbatasan kemampuan pemerintah dan masyarakat, serta iselenggarakan secaraaman dan memuaskan sesuai dengan norma dan etika yang baik (M. Dewi, 2016). Peningkatan mutu pelayanan dan kepuasan konsumen atau pasien menjadi salah satu strategi penting yang tidak dapat diabaikan oleh para penentu kebijakan di puskesmas. Peningkatan mutu dalam pelayanan kesehatan selain berorientasi kepada proses pelayanan yang bermutu, juga pada hasil mutu pelayanan kesehatan yang sesuai dengan keinginan konsumen atau pasien, dengan tetap mengacu pada kode etik profesi (Anjayati, 2021; Kosnan, 2020; Putri et al., 2018). Seiring meningkatnya kedasaran masyarakat betapa berharganya kesehatan bagi hidup mereka karena mengetahui mahalnya biaya perawatan kesehatan yang sering membuat masyarakat kesulitan untuk mendapatkan pelayanan kesehatan dengan baik sesuai dengan harapan merka (Gunawan \& Saragih, 2019). 
Pelayanan yang baik menghasilkan kepuasan yang hubungannya berbanding lurus, semakin baik pelayanan yang diberikan maka konsumen akan semakin puas. Konsumen akan berusaha menari pelayanan yang terbaik kepadanya (Aulia et al., 2017). Kepuasan dapat dirasakan ketika konsumen merasakan sebuah kualitas. Dengan demikian rumah sakit atau puskesmas merupakan salah satu pelaku pelayanan kesehatan yang kompetitif harus dikelola oleh pelaku yang mempunyai jiwa wirausaha yang mampu menciptakan efisiensi, keunggulan dalam kualitas dan pelayanan, keunggulan dalam inovasi serta unggul dalam merespon kebutuhan pasien (Ayuningrum et al., 2013; Setryorini, 2018). Temuan penelitian terdahulu menunjukkan bahwa kualitas pelayanan mempengaruhi kepuasan pasien (Engkus, 2019b). Kualitas pelayanan berpengaruh positif dan signifikan terhadap kepuasan pasien (Enas, 2020). Temuan lain menunjukkan kualitas pelayanan rumah sakit berhubungan positif dengan kepuasan pasien (Putri et al., 2018). Adanya hubungan kualitas pelayanan kesehatan dengan kepuasan pasien (Anjayati, 2021). Tujuan dari penelitian ini yaitu untuk menganalisisi kualitas pelayanan terhadap kepuasan pasien Puskesmas Banja Loweh di Kabupaten Lima Puluh Kota. Penelitian ini juga mendeskripsikan pengaruh bukti langsung (tangible), kehandalan (reliability), depat tanggap (responsiveness), jaminan (assurance), empati (empathy) terhadap kepuasan pasien.

\section{METODE}

Jenis penelitian ini adalah penelitian kuantitatif dengan tujuan untuk menguji hipotesisi yang telah ditetapkan kemudian menginterprestasikan hasil tersebut untuk memperoleh kesimpulan (Gofur, 2019). Populasi dalam penelitian ini yaitu seluruh pasien di Puskesmas Banja Loweh di Kabupaten Lima Puluh Kota. Teknik pengambilan sampel yang digunakan yaitu non-probability sampling (purposive sampling), criteria pengambilan sampel yang pasien yang sudah pernah berkunjung ke puskesmas Puskesmas Banja Loweh di Kabupaten Lima Puluh Kota dan penelitian ini membutuhkan 100 orang responden. Penelitian ini menggunakan data primer yang diperoleh dari responden dengan menjawab pertanyaan melalui kuesioner yang disebarkan. Di dalam penelitian ini responden akan menjawab beberapa pertanyaan terkait kualitas pelayanan dan kepuasan di Puskesmas Banja Loweh di Kabupaten Lima Puluh Kota. Skala ordinal yang digunakan adalah sekala likert yang dapat menaytakan tingkat kesetujuan atau ketidak kesetujuan responden akan pertanyaan yang diberikan. Kemudian responden akan memberikan satu tnada pada kolom skala SS (sangat setuju), S (Setuju), TS (tidak setuju) atau STS (sangat tidak setuju) untuk setiap pertanyaannya(Panjaitan, 2016).

Pengujian instrumen pada penelitin ini dengan uji validitas dan reliabilitas. Pengujian validitas meurpakan suatu skala pengukuran bila melakukan apa yang seharusnya dilakukan dan mengukur apa yang seharusnya diukur. Bila korelasi di atas 0,361, maka dapat disimpulkan pertanyaan dalam kuesioner tersebut valid. Hasil pengujuan menunjukkan bahwa masing-masing item pertanyaan pada kuesioner menghasilkan nilai $r$ hitung > r table. Maka dapat disimpulkan bahwa butir pertanyaan atau kueisoner pada variable kualiatas pelayanan dan kepuasan dinyatakan valid. Pengujian reliabilitas digunaka dalam mengetahui apakah point pertanyaan pada kuesioner yang digunakan telah menunjukkan tingkat keakuran dan konsistensi dengan melihat Conbach's Alpha. Kuesioner dinyatakan reliable ketika conbach alpha > 0,60 . Hasil pengujuan reliabilitas menunjukkan hasil cronbach alpha pada instrument memiliki nilai di atas 0,6 pada variable kepuasan sebesar 0,820 dan kualitas pelayanan sebesar 0,910, maka dapat disimpulkan bahwa instrument pada penelitian ini reliable. Metode dan teknik analisis data dengan teknik regresi berganda dan menggunakan SPSS sebgai perhitungan analisis data (Kadir et al., 2018; Padilah \& Adam, 2019). Perlu melakukan uji validitas dan uji reliabilitas pada instrument penelitian. Kemudian dilakukan pengujian asumsi klasisk terlebih dahulu untuk memperoleh keputusan yang memenuhi beberap asumsi dasar (Firdiyansyah, 2017). Pengujian asumsi klasik yang dilakukan adalah uji normalitas, uji multikolinearitas, dan uji heterokedastisitas. Regresi linear berganda berfungsi untuk melihat hubungan linier antara variable bebas dan variable terikat.

\section{HASIL DAN PEMBAHASAN}

\section{Hasil}

Peneltiian ini menggunakan data primer yang diperoleh dari responden dengan menjawab pertanyaan melalui kuesioner yang disebarkan. Pengujian asumsi klasik yang dilakukan adalah uji noermalitas, uji multikolinearitas dan uji heterokedastisitas. Setelah dinyatakan lolos dalam uji asumsi klasik, kemudian dilakukan uji regresi berganda. Statistik deskriptif merupakan gambaran responden mengenai variable yang ada dalam penelitian supaya dapat mengetahui bentuk distribusi frekuensi absolute. 
Tabel 1. Statistik Deskriptif

\begin{tabular}{llllll}
\hline Variabel & N & Min & Maks & Rata-rata & Std. Deviasi \\
\hline Kepuasan Pasien & 100 & 7 & 15 & 11,90 & 1.95 \\
Tangible & 100 & 16 & 26 & 22,28 & 2.17 \\
Reliability & 100 & 12 & 22 & 18,72 & 2.07 \\
Responsiveness & 100 & 11 & 22 & 18,25 & 2,22 \\
Assurance & 100 & 16 & 23 & 20,24 & 1,75 \\
Empaty & 100 & 15 & 24 & 18,65 & 1,71 \\
\hline
\end{tabular}

Nilai maksimum dari variable kepuasan pasien yaitu 15 dan nilai minimum sebesar 7. Nilai rata-rata sebesar 11,90 dengan standar deviasi 1,95. Variable tangible niliai masimum sebesar 26 dan nilai minimum sebesar 16. Nilai rata-rata sebesar 22,28 dengan standar devaisi sebesar 2,17. Variable reliability nilai maksimum sebesar 22 dan nilai minimum sebesar 12. Nilai rata-rata sebesar 18,72 dengan standar deviasi 2,07, variable responsiveness nilai maksimum sebesar 22 dan nilai min 11. Nilai rata-rata 18,25 dengan standar deviasi 2,22. Variabel assurance nilai maksimum sebesar 23 dan nilai minimum sebesar 16 . Nilai rata-rata 20,24 dengan standar deviasi 1,75. Variable emphaty nilai maksimum sebesar 24 dan nilai minimum sebesar 15. Nilai rata-rata 18,65 dengan standar deviasi sebesar 1,71. Pengujian normalitas menggunakan statistic sederhana dengan menggunakan kolmogorov smirnov. Penelitian dikatakan berdistribusi normal dengan melihat nilai signifikansi variable, jika nilai signifikansi lebih besar dari alpha $5 \%(0,05)$, maka data menunjukkan berdistribusi normal. Hasil pengujian normalitas menunjukkan nilai signifikansi pada pengujian normalitas sebesar 0,789. Hal ini berarti nilai signifikansi lebih besar dari batas minimal nilai residual 0,05. Maka data pada penelitian terdistribusi normal.

Uji mulitkolinearitas digunakan untuk mengetahui ada tidaknya gejala dengan memperhatikan nilai VIF (Variance Inflation Factor) dan Nilai tolerance-nya. Jika nilai VIF kurang dari 10 dan nilai tolerance-nya lebih besar dari alpha $10 \%(0,1)$ data dalam penelitian bebas dari multiklonilearitas. Hasil pengujian multikolinearitas menujukkan bahwa variable dalam penelitian ini memiliki nilai tolerance-nya lebih besar dari alpha $10 \%(0,1)$ dan nilai Vif kesil dari 10. Nilai tolerance variabel tangible sebesar 0,510 dan nilai VIF sebesar 1,963. Nilai tolerance variabel reliabel sebesar 0,547 dan nilai VIF sebesar 1,827. Nilai tolerance variabel responsiveness sebesar 0,979 dan nilai VIF sebesar 1,021. Nilai tolerance variabel assurance sebesar 0,717 dan nilai VIF sebesar 1,394. Nilai tolerance variabel emphaty sebesar 0,937 dan nilai VIF sebesar 1,068. Hasil pengujian heterokedastisitas menunjukkan bahwa variable tangible memiliki nilai sig 0,865 , variable reliability memiliki nilai sig 0,752 , variable responsiveness memiliki nilai sig 0,052 , variable assurance memiliki nilai sig 0,567 dan variable emphaty memiliki nilai sig 0,554. Pengujian hipotesi penelitian ini menggunakan teknik analisis regresi linear berganda. Pengujian dilakukan dengan menggunakan aplikasi SPSS dengan hasil analisis yang diperoleh dapat dilihat pada Tabel 2.

Tabel 2. Hasil Uji T Regresi

\begin{tabular}{|c|c|c|c|c|c|c|}
\hline & \multirow{2}{*}{ Model } & \multicolumn{2}{|c|}{ Unstandardized Coefficients } & \multirow{2}{*}{$\mathbf{t}$} & \multirow{2}{*}{ Sig. } & \multirow{2}{*}{ Keterangan } \\
\hline & & B & Std. Error & & & \\
\hline \multirow[t]{6}{*}{1} & (Constant) & $-11,132$ & 2,526 & $-4,408$ & 0,000 & \\
\hline & Tangible & 0,342 & 0,083 & 4,114 & 0,000 & HI diterima \\
\hline & Reliability & 0,311 & 0,084 & 3,694 & 0,000 & HI diterima \\
\hline & Responsiveness & 0,158 & 0,059 & 2,688 & 0,008 & HI diterima \\
\hline & Assurance & 0,183 & 0,087 & 2,100 & 0,038 & HI diterima \\
\hline & Emphaty & 0,161 & 0,078 & 2,064 & 0,042 & HI diterima \\
\hline \multicolumn{2}{|c|}{ R-Square } & & & & 0,588 & \\
\hline \multicolumn{2}{|c|}{ F hitung } & & & & 26,817 & \\
\hline \multicolumn{2}{|c|}{ Sig. F } & & & & 0,000 & \\
\hline
\end{tabular}

Berdasarkan hasil pengujian data kualitas pelayanan dilihat dari tangible, menunjukkan nilai signifikansi $0,000<$ nilai alpha sebesar 0,05 . Nilai koefisien regresi sebesar 0,342 membuktikan bahwa tangible berpengaruh positif terhadap kepuasan pasien, maka HI pada penelitian di terima. Reliability menunjukkan nilai signifikansi $0,000<$ nilai alpha sebesar 0,05. Nilai koefisien regresi sebesar 0,311 membuktikan bahwa relibility berpengaruh positif terhadap kepuasan pasien, maka $\mathrm{H} 2$ pada penelitian di terima. Responsiveness menunjukkan nilai signifikansi 0,008 < nilai alpha sebesar 0,05. Nilai koefisien regresi sebesar 0,1582 membuktikan bahwa responsiveness berpengaruh positif terhadap kepuasan pasien, 
maka H3 pada penelitian di terima. Assurance menunjukkan nilai signifikansi $0,038<$ nilai alpha sebesar 0,05. Nilai koefisien regresi sebesar 0,183 membuktikan bahwa assurance berpengaruh positif terhadap kepuasan pasien, maka H4 pada penelitian di terima. Emphaty menunjukkan nilai signifikansi 0,042< nilai alpha sebesar 0,05. Nilai koefisien regresi sebesar 0,161 membuktikan bahwa emphaty berpengaruh positif terhadap kepuasan pasien, maka H5 pada penelitian di terima. Pengujian koefisien determinansi mendapatkan nilai adjusted $r$-squared sebesar 0,588. Berdasarkan nilai tersebut menunjukkan bahwa variable kualitas pelayanan dilihat dari dimensi tabible, reliability, responesivene, assurance dan emphaty dapat mempengaruhi kepuasan pasien sebesar 58,8\% sedangkan sisanya dipengaruhi oleh variable lain di luar penelitian. Nilai F hitung didapat sebesar 26,817 dan nilai signifikansi 0,000. Hal tersebut membuktikan varibel independen dalam penelitian terbukti secara simultan memiliki pengaruh yang signifiak terhadap variable kepuasan pasien.

\section{Pembahasan}

Penelitian ini adalah penelitian kuantitatif dengan menggunakan data primer yang diperoleh dari responden menjawab pertanyaan melalui kuesioner yang disebarkan. Di dalam penelitian ini responden akan menjawab beberapa pertanyaan terkait kualitas pelayanan dan kepuasan di Puskesmas Banja Loweh di Kabupaten Lima Puluh Kota. Berdasarkan hasil analisis diperoleh beberapa temuan. Pertama, pengaruh kualitas pelayan dimensi tangible terhadap kepuasan pasien. Hasil pengujian membuktikan kualitas pelayanan dimensi tangible berpengaruh positif dan signifikan terhadap kepuasan pasien Puskesmas Banja Loweh di Kabupaten Lima Puluh Kota. Hal ini berarti bahwa peningkatan pada unsur-unsur fisik dapat meningkatkan kepuasan pasien, sebaliknya penurunan unsure fisik juga akan menyebabkan penurunan kepuasan pasien. Dimensi berwujud adalah penampilan dan kemampuan sarana dan prasarana fisik yang dapat diandalkan. Berwujud menakup kenyamanan kamar rawat inap, kebersihan lingkungan, penampilan tenaga medis, dan kelengkapan fasilitas pelayanan (Ayuningrum et al., 2013). Dimensi tangible merupakan dimensi yang paling dominan berpengaruh terhadap kepuasan pasien. Suatu Puskesmas agar bisa operasional, tidak cukup mempunyai sumber daya manusia saja, tetapi harus didukung pula oleh fasilitas penunjang Puskesmas baik penunjang medis maupun non medis, serta sarana penunjang rumah sakit antara lain meliputi: laboratorium, instalasi farmasi, radiologi, pelayanan makan pasien, dan lain-lain. Fasilitas penunjang puskesmas juga sangat menentukan terhadap kualitas pelayanan rumah sakit sehingga mempengaruhi kepuasan pasien, khususnya rawat inap. Selain itu (Kosnan, 2020) menyatakan bahwa fasilitas merupakan sarana maupun prasarana yang penting dalam usaha meningkatkan kepuasan seperti member kemudahan, memenuhi kebutuhan dan kenyamanan bagi pengguna jasa. Apabila fasilitas yang disediakan sesuai dengan kebutuhan, maka konsumen akan merasa puas. Pasien akan memberikan penilaian (reaksi afeksi) terhadap sarana dan prasarana kesehatan yang terkait dengan penyelenggaraan pelayanan kesehatan. Temuan penelitian ini didukung penelitian terdahulu menyatakan bahwa dengan hasilnya menyatakan bahwa bukti fisik berpengaruh terhadap kepuasan pasien (Aulia et al., 2017; Rosalia \& Purnawat, 2018). Dimensi bukti fisik berpengaruh positif dan signifikan terhadap kepusan pasien (Noprianty, 2019). Kualitias pelayanan informasi obat dimensi tangible memberikan pengaruh yang signifikan terhadap kepuasan pasisen (Mayefis et al., 2015). Variabel yang paling dominan berpengaruh terhadap kepuasan Pasien Rawat Inap (Enas, 2020).

Kedua, pengaruh kualitas pelayan dimensi reliability terhadap kepuasan pasien. Hasil pengujian membuktikan kualitas pelayanan dimensi reliability berpengaruh positif dan signifikan terhadap kepuasan pasien Puskesmas Banja Loweh di Kabupaten Lima Puluh Kota. Dimana semakin tinggi dimensi keandalan yang diberikan, maka semakin tinggi pula kepusan pasien. Dimensi keandalan ini penting untuk mencapai kepuasan pasien. Kehandalan juga merupakan faktor paling dominan yang mempengaruhi kepuasan pelanggan (Ayuningrum et al., 2013; 0. Dewi et al., 2021). Temuan penelitian ini dengan temuan penelitian sebelumnya yang menyatakan bahwa bukti fisik berpengaruh terhadap kepuasan pasien (Kosnan, 2020). Keandalan berpengaruh positif dan signifikan terhadap kepuasan pasien. Kualitias pelayanan informasi obat dimensi reliability memberikan pengaruh yang signifikan terhadap kepuasan pasisen (Arditama \& Lestari, 2020). Ketiga, pengaruh kualitas pelayan dimensi responsiveness terhadap kepuasan pasien. Hasil pengujian membuktikan kualitas pelayanan dimensi responsiveness berpengaruh positif dan signifikan terhadap kepuasan pasien Puskesmas Banja Loweh di Kabupaten Lima Puluh Kota. Dimana semakin tinggi dimensi keandalan yang diberikan, maka semakin tinggi pula kepusan pasien. Dimensi keandalan ini penting untuk mencapai kepuasan pasien.. Dimensi responsiveness merupakan dimensi paling rendah yang berpengaruh terhadap kepuasan pasien. Temuan penelitian ini didukung penelitian terdahulu menyatakan bahwa daya tangap berpengaruh terhadap kepuasan pasien (Rosalia \& Purnawat, 2018). Daya tanggap berpengaruh positif dan signifikan terhadap kepuasan pasien (Ayuningrum et al., 2013). Terdapat pengaruh positif dan signifikan daya tanggap terhadap kepuasan pasien (Mayefis et al., 2015). Kualitias pelayanan informasi obat dimensi responesiveness memberikan pengaruh yang signifikan terhadap kepuasan pasisen. Dimensi yang 
mempunyai pengaruh paling kecil adalah dimensi daya tanggap (Engkus, 2019b). Mutu pelayanan di rumah sakit swasta di Chenai India dengan 385 responden menemukan bahwa daya tanggap (responsiveness) berhubungan secara bermakna dengan kepuasan pasien (Essiam, 2013). Keempat, pengaruh kualitas pelayan dimensi assurance terhadap kepuasan pasien. Hasil pengujian membuktikan kualitas pelayanan dimensi assurance berpengaruh positif dan signifikan terhadap kepuasan pasien Puskesmas Banja Loweh di Kabupaten Lima Puluh Kota. Dimana semakin baik assurance yang diebrikan maka semakin tinggi pula kepuasan pasien. Jaminan merupakan factor penentu kenyamanan dan keamanan pasien selama dalam perawatan di Puskesmas. Temuan penelitian ini didukung penelitian terdahulu menyatakan bahwa dengan hasilnya menyatakan bahwa jaminan berpengaruh terhadap kepuasan pasien (Rosalia \& Purnawat, 2018). Jaminan berpengaruh positif dan signifikan terhadap kepuasan pasien (Ayuningrum et al., 2013). Dimensi jaminan berpengaruh positif dan signifikan terhadap kepuasan pasien (Aulia et al., 2017). Kualitias pelayanan informasi obat dimensi anssurance memberikan pengaruh yang signifikan terhadap kepuasan pasisen (Mayefis et al., 2015; Scher et al., 2017).

Kelima, pengaruh kualitas pelayan dimensi emphaty terhadap kepuasan pasien. Hasil pengujian membuktikan kualitas pelayanan dimensi emphaty berpengaruh positif dan signifikan terhadap kepuasan pasien Puskesmas Banja Loweh di Kabupaten Lima Puluh Kota. Hal ini berarti bahwa semakin empati yang diberikan oleh pengelolan puskesm ,maka semakin tinggi pula kepuasan pelanggan. Karena empati sangat dibutuhkan oleh orang yangs edang sakit atau sedang dalam perawatan. Apabila empati yang diberikan tidak sesuai maka pasien tidak akan menggunakan jasa puskesma tersebut apalagi merekomendasikan kepada orang lain (Ayuningrum et al., 2013). Temuan penelitian ini didukung penelitian terdahulu menyatakan bahwa bukti fisik berpengaruh terhadap kepuasan pasien (Rosalia \& Purnawat, 2018). (Sitio \& Ali, 2019) menyatakan bahwa Dimensi kualitas pelayanan yang paling berpengaruh terhadap kepuasan pasien adalah dimensi Empati. pasien. Dimensi empati berpangaruh signifikan terhadap kepuasan pasien (Mayefis et al., 2015; Shabbir et al., 2016). (Mayefis et al., 2015) Kualitas pelayanan informasi obat dimensi emphaty memberikan pengaruh yang signifikan terhadap kepuasan pasisen. Kualitas pelayanan yang mempunyai pengaruh paling besar terhadap kepuasan pasien adalah dimensi jaminan. dimensi emphaty memang sering dianggap tidak terlalu penting oleh para perawat (Engkus, 2019b; Kosnan, 2020). Namun bagi pasien dari kalangan tertentu (menengah ke atas) unsur ini menjadi hal yang cukup penting. Mereka merasa ego, status, dan gengsinya tetap terpelihara atau bahkan terus menerus ditingkatkan dihadapan banyak orang.

\section{SIMPULAN}

Pelayanan berpengaruh positif terhadap kepuasan pasien Puskesms Banja Loweh di Kabupaten Lima Puluh Kota. Hal ini menunjukkan bahwa pasien merasa puas jika kualitas pelayanan sesuai dengan keinginan pasien. Jika dilihat dari masing-masing dimensi kualitas pelayanan dimana dimensi tangible, reliability, responsiveness, assurance dan emphaty berpengaruh signifikan baik secara parsial maupun simultan terhadap kepuasan pasien di Puskesms Banja Loweh di Kabupaten Lima Puluh Kota. Adapun dimensi yang paling dominan berpengaruh terhadap kepuasan pasien yaitu dimensi tangible. Sedangkan dimensi yang terendah pengaruhnya kepuasan pasien yaitu responsiveness. Oleh karena itu Puskesms Banja Loweh di Kabupaten Lima Puluh Kota. Wajib meningkatkan kualitas pelayanan secara terus menerus untuk menarik pasien agar merasa nyaman dan senang ketika berobat.

\section{DAFTAR PUSTAKA}

Al-Azzam, D. A. F. M. (2020). The Impact of Evaluating Service Quality Dimensions on Patient Satisfaction: A Study of Private Hospitals in Irbid City / Jordan. International Journal of Business and Social Science, 11(7), 11-21. https://doi.org/10.30845/ijbss.v11n7a2.

Anjayati, S. (2021). Review Artikel: Analisis Kualitas Pelayanan Terhadap Kepuasan Pasien Di Puskesmas Menggunakan Metode Servqual. Nursing Care and Health Technology Journal (NCHAT), 1(1), 31-38. http://ojs.nchat.id/index.php/nchat/article/view/7.

Arditama, E., \& Lestari, P. (2020). Obstacles and Challenges of Indonesia'S Micro, Small and Medium Enterprises (Umkm) in Facing the Covid-19 Pandemic. Jurnal Pendidikan Kewarganegaraan Undiksha, 8(1), 35-46. https://doi.org/10.23887/jpku.v8i3.28610.

Aulia, R., Adhani, R., \& Irham Taufiqurrahman, I. H. (2017). Terhadap Kepuasan Pasien Bpjs Di Layanan Primer. Kedokteran Gigi, II(1), 95-100. http://ppjp.unlam.ac.id/journal/index.php/dentino/article/view/2608/2266.

Ayuningrum, H., Immas, P., \& Dewi, R. S. (2013). Pengaruh kualitas pelayanan terhadap kepuasan pasien di Rumah Sakit Islam Kota Magelang. Jurnal Ilmu Administrasi Bisnis, 2(3), 110-116. 
https://ejournal3.undip.ac.id/index.php/jiab/article/view/2992.

Darmawan, P. A. D. T., \& Ekawati, N. W. (2017). Pengaruh Kepuasan Konsumen Memediasi Harga terhadap Loyalitas Konsumen dalam Berbelanja pada Florist Online di Denpasar. E-Jurnal Manajemen Unud, 6(4), 2076-2104. https://ocs.unud.ac.id/index.php/Manajemen/article/view/27970.

Dewi, M. (2016). Pengaruh Kualitas Pelayanan terhadap Kepuasan Pasien Pengguna BPJS pada Rumah Sakit Rehabilitasi Medik Kabupaten Aceh Timur. Jurnal Manajemen Dan Keuangan Unsam, 5(2), 535-544. https://doi.org/10.23917/dayasaing.v18i2.4511.

Dewi, O., Raviola, R., \& Sari, N. P. (2021). Analisis Survei Kepuasan Pelanggan Terhadap Mutu Pelayanan Di Rumah Sakit Jiwa Tampan Provinsi Riau. Jurnal Kesehatan Komunitas, 7(1). https://doi.org/10.25311/keskom.Vol7.Iss1.874.

Enas, U. (2020). Pengaruh Kualitas Pelayanan Terhadap Kepuasan Pasien the Effect of Service Quality Against Patient Satisfaction in. Jurnal Kesehatan Ilmu Kaperawatan, 20(1), 126-133.

Engkus. (2019a). Pengaruh Kualitas Pelayanan Terhadap Kepuasan Pasien Di Puskesmas Cibitung Kabupaten Sukabumi. Jurnal Governansi, https://doi.org/103.41.206.194/JGS/article/view/1956.

Engkus, E. (2019b). Pengaruh Kualitas Pelayanan Terhadap Kepuasan Pasien di Puskesmas Cibitung Kabupaten Sukabumi. Jurnal Governansi, 5(2), 99-109. https://doi.org/10.30997/jgs.v5i2.1956.

Essiam, J. (2013). Service Quality and Patients Satisfaction with Healthcare Delivery: Empirical Evidence from Patients of the Out Patient Department of a Public University Hospital in Ghana. European Journal of Bussiness and Managment, 5(28), 52-63.

Gofur, A. (2019). Pengaruh Kualitas Pelayanan dan Harga terhadap Kepuasan Pelanggan. Jurnal Riset Manajemen Dan Bisnis (JRMB) Fakultas Ekonomi UNIAT, 4(1), 37-44. https://doi.org/10.36226/jrmb.v4i1.240.

Gunawan, Y. I., \& Saragih, M. (2019). Pengaruh Kualitas Pelayanan Medis Dan Inovasi Layanan Administrasi Terhadap Kepuasan Pasien. Jurnal Manajemen Kewirausahaan, 16(1), 33. https://doi.org/10.33370/jmk.v16i1.301.

Haryoko, U. B., Delimah Pasaribu, V. L., \& Ardiyansyah, A. (2020). Pengaruh Harga Dan Kualitas Pelayanan Terhadap Kepuasan Konsumen Pada Firman Dekorasi (Wedding Organizer). Point, 2(1). https://doi.org/10.46918/point.v2i1.566.

Kadir, A., Basri, M., \& Rodi, R. (2018). Pengaruh Kualitas Pelayanan Terhadap Kepuasan, Nilai, Kepercayaan Dan Loyalitas Pelanggan Rumah Tangga Pada Perusahaan Daerah Air Minum Kota Kendari. Journal Publicuho, 1(1), 28. https://doi.org/10.35817/jpu.v1i1.7297.

Kosnan, W. (2020). Pengaruh Kualitas Pelayanan Terhadap Kepuasan Pasien Rawat Inap Di Rumah Sakit Umum Daerah Kabupaten Merauke. Jurnal Ekonomi, Bisnis, Dan Akuntansi, 21(4). https://doi.org/10.32424/jeba.v21i4.1538.

Mayefis, D., Halim, A., \& Rahim, R. (2015). Pengaruh Kualitas Pelayanan Informasi Obat terhadap Kepuasan Pasien Apotek X Kota Padang ( Effect of Drug Information Service Quality Patient Satisfaction City Pharmacy X Padang ). Jurnal Ilmu Kefarmasian Indonesia, 13(2), 201-204. http://jifi.farmasi.univpancasila.ac.id/index.php/jifi/article/view/86.

Neupane, R., \& Devkota, M. (2017). Evaluation of the Impacts of Service Quality Dimensions on Patient/Customer Satisfaction: A Study of Private Hospitals in Nepal. International Journal of Social Sciences and Management, 4(3), 165-176. https://doi.org/10.3126/ijssm.v4i3.17520.

Noprianty, R. (2019). Jenjang Karir Perawat dan Kepuasan Pasien terhadap Kualitas Pelayanan Keperawatan. Jurnal Pendidikan Keperawatan Indonesia, 5(2), 146 - 156. https://doi.org/10.17509/jpki.v5i2.17404.

Nuryati, S. (2017). Evaluasi Implementasi Sistem Manajemen Mutu ISO 9001:2008 di Puskesmas Wilayah Kabupaten Sleman. Jurnal Medicoeticolegal Dan Manajemen Rumah Sakit, 6(2), 128-135. https://doi.org/10.18196/jmmr.6137.

Ofela, H. (2016). Pengaruh harga, kualitas produk dan kualitas pelayanan terhadap kepuasan konsumen kebab kingabi. Jurnal Ilmu Dan Riset Manajemen, 5(1), 1-15. http://jurnalmahasiswa.stiesia.ac.id/index.php/jirm/article/download/423/432.

Padilah, T. N., \& Adam, R. I. (2019). Analisis Regresi Linier Berganda Dalam Estimasi Produktivitas Tanaman Padi Di Kabupaten Karawang. FIBONACCI: Jurnal Pendidikan Matematika Dan Matematika, 5(2), 117. https://doi.org/10.24853/fbc.5.2.117-128.

Panjaitan, I. (2016). Price, Quality Service, Interests Buy, Customer Satisfaction. 19(2), 43-55.

Pelayanan, P. K., \& Terhadap, D. A. N. L. (2017). KEPRI MALL KOTA BATAM Indra Firdiyansyah * Program Studi Manajemen, Sekolah Tinggi Ilmu Ekonomi Galileo Komplek Plaza Sulaiman Blok A No : 4-6 Jl . Sultan Abdurrahman , Lubuk Baja , Kota Batam Provinsi Kepulauan Riau Telp : ( 0778 ) 433703 Email : indra. 1-9. 
Putri, L. E., Dachriyanus, D., \& Putri, N. T. (2018). Pengaruh Kualitas Pelayanan Kefarmasian terhadap Kepuasan Pasien Rawat Inap RSUP Dr. M. Djamil Padang. Jurnal Optimasi Sistem Industri, 17(2), 152. https://doi.org/10.25077/josi.v17.n2.p152-161.2018.

Rafiah, K. K. (2019). Analisis Pengaruh Kepuasan Pelanggan dan Kepercayaan Pelanggan terhadap Loyalitas Pelanggan dalam Berbelanja melalui E-commerce di Indonesia. Al Tijarah, 5(1), 46-56. https://doi.org/10.21111/tijarah.v5i1.3621.

Rosalia, K. J., \& Purnawat, N. K. (2018). Pengaruh Kualitas Pelayanan Terhadap Kepuasan Pasien RSU Surya Husadha di Denpasar. E-Jurnal Manajemen Unud, 7(5), 2442-2469. https://doi.org/10.24843/EJMUNUD.2018.v7.i05.p.

Scher, C., Meador, L., Cleave, J. H. Van, \& Reid, M. C. (2017). Review Article Moving Beyond Pain as the Fifth Vital Sign and Patient Satisfaction Scores to Improve Pain Care in the 21st Century. Pain Management Nursing, 1-5. https://doi.org/10.1016/j.pmn.2017.10.010.

Setryorini, U. (2018). Analisis Pengaruh Kualitas Pelayanan Terhadap Kepuasan Pasien (Studi Kasus Pada Pasien Pengguna BPJS RSI Masyithoh Bangil). Jurnal Ilmu Manajemen, 2(1), 1-7. https://jurnal.narotama.ac.id/index.php/mgs/article/view/568.

Shabbir, A., Malik, S. A., \& Malik, S. A. (2016). Measuring patients' healthcare service quality perceptions, satisfaction, and loyalty in public and private sector hospitals in Pakistan. International Journal of Quality and Reliability Management, 33(5), 538-557. https://doi.org/10.1108/IJQRM-06-20140074.

Sitio, T., \& Ali, H. (2019). Patient Satisfaction Model and Patient Loyalty: Analysis of Service Quality and Facility ( Case Study at Rawamangun Special Surgery Hospital). 9771, 551-559. https://doi.org/10.36348/sb.2019.v05i10.002.

Sukarni, Sudirman, \& Yusuf, H. (2020). Hubungan Konseling Keluarga Berencana dan Pengetahuan Ibu Dengan Pemilihan Metode Kontrasepsi Di Wilayah Kerja Puskesmas Mamboro. Jurnal Kolaboratif Sains, 1(1), 339-348. https://doi.org/10.31934/jom.v1i1.1182.

Tores, R. (2018). Pengaruh Kualitas Pelayanan Terhadap Kepuasan Pasien Pada Puskesmas Tanah Abang Kecamatan Batanghari Leko. Jurnal Manajemen Kompeten, 1(1), 60. https://doi.org/10.51877/mnjm.v1i1.20. 